\title{
Coupling between macrofauna community structure and beach type: a deconstructive meta-analysis
}

\author{
Omar Defeo $^{1, *}$, Anton McLachlan ${ }^{2}$ \\ ${ }^{1}$ UNDECIMAR, Facultad de Ciencias, Iguá 4225, 11400 Montevideo, Uruguay \\ ${ }^{2}$ The University of Sydney, New South Wales 2006, Australia
}

\begin{abstract}
Species richness and abundance of macrofauna on sandy shores increase from microtidal reflective to macrotidal dissipative beach conditions. However, no attempt has been made to deconstruct these patterns. Using information on the macrofauna from 63 microtidal sandy beach surveys in South America, we deconstructed the community to discriminate among taxonomic groups, supralittoral and intertidal forms, and groups with different feeding habits and development modes. We also separated the effects of development mode and beach zone (intertidal vs. supralittoral) at the species level and scaled body size to density estimates. Total species richness decreased towards reflective beaches, but this trend was less marked in crustaceans than in molluscs or polychaetes. Supralittoral air-breathing crustaceans increased in richness and abundance from dissipative to reflective conditions, a reverse trend to that seen in intertidal crustaceans. Development modes (species with direct development and with planktonic larvae) showed the same response to beach type as the community as a whole. Filter feeders, scavengers and deposit feeders showed the same trend, but the latter were scarce or absent on reflective beaches. Zone was more important than either development or feeding modes in determining individual species responses to beach type. Body size decreased and density increased from reflective to dissipative beaches, suggesting that smaller forms are more sensitive to harsh conditions where density is lower, and hence there is less scope for biological interactions in reflective beaches. The deconstruction approach provided insights into the relationships between life cycle characteristics and richness and abundance patterns and the relative importance of environmental variables in beach ecology.
\end{abstract}

KEY WORDS: Species richness $\cdot$ Sandy beaches $\cdot$ Deconstruction $\cdot$ Morphodynamics $\cdot$ Body size Resale or republication not permitted without written consent of the publisher

\section{INTRODUCTION}

The effects of scale, latitudinal, altitudinal and depth gradients on species richness have been considered from the perspectives of ecological and historical biogeography (Wiens \& Donoghue 2004, Bonada et al. 2009). In terrestrial systems, for example, climate plays important roles at large scales (Currie et al. 2004) and productivity is also a determinant of species richness (Field et al. 2009). At regional and local scales, patterns of richness are influenced by factors such as dispersal, evolutionary history and habitat variability (Blamires et al. 2008). Recently, Marquet et al. (2004) have argued for deconstructing biodiversity, i.e. considering richness patterns separately for different groups of species. For example, species may be grouped by taxonomic affiliation, body size, mode or mobility. Such groups may respond differently to the environment and exhibit contrasting patterns, which would be obscured if only aggregate richness is considered. By treating such species groups separately and considering their richness at different scales, a more complete understanding of the factors driving species richness patterns may emerge. In marine and aquatic systems, these issues are less clear (Field et al. 2009) and all studies on deconstructing richness to date have been based on terrestrial systems (e.g. Blamires et al. 2008, Terribile et al. 2009), except for a recent study on patterns in southeastern Pacific benthos based on larval development mode (Fernández et al. 2009). 
Much has been written on benthic diversity in marine and intertidal ecosystems since the seminal review of Sanders (1968). Nevertheless, although sandy beaches dominate the world's temperate and tropical coastlines, biodiversity of their benthic macrofauna has received attention only quite recently. Ocean beaches are defined by the interactions between tides, wave energy and the sand particle size available for sorting and transport by the tides and waves. These interactions produce a range of beach morphodynamic types which span a continuum from narrow and steep microtidal reflective beaches to macrotidal dissipative systems, the latter being wide and flat and grading into tidal flats under conditions of large tides (Short 1996). Reflective beaches are coarsegrained and have narrow surf zones, whereas dissipative beaches have finer sediments and extensive surf zones.

The relationship between physical beach type (slope, particle size) and intertidal macrofauna communities reveals increasing species richness and abundance from reflective to dissipative beaches (McLachlan et al. 1981, McLachlan 1990, Defeo et al. 1992, Jaramillo et al. 1995). A recent meta-analysis of data from 4 continents (161 beaches in 10 countries) confirmed that species richness increases from microtidal reflective beaches to macrotidal dissipative beaches, and from temperate areas to the tropics (McLachlan \& Dorvlo 2005). However, all these studies considered all macrofauna in aggregate and did not differentiate between taxa or other groups of species. Richness of marine macrobenthic species on sandy beaches increases with beach width according to a semi-log model (McLachlan \& Dorvlo 2007a), suggesting that beaches act as isolated rather than contiguous habitats. Further, the finding that species richness increases more rapidly than expected in response to widening beaches indicates that wider (dissipative) beaches present more favourable habitats for benthic macrofauna. Thus, tropical beaches harbour the greatest species pool, whereas wide macrotidal dissipative beaches harbour the greatest proportion of the species pool in an area (Soares 2003).

Supralittoral species, i.e. those living above the drift line or high water mark, are not normally exposed to marine conditions and may respond quite differently to beach type (Defeo \& Gómez 2005). These forms, which are mainly direct developers, are common on reflective beaches, which usually have a distinct berm that is not inundated. In contrast, intertidal forms, which mainly display indirect development (broadcast spawning with external fertilization and planktonic larvae), are sparse on reflective beaches. Therefore, different components of the community may not respond similarly to changes in beach type. However, no studies have con- sidered richness in relation to development mechanisms or taxonomic groups. One meta-study has shown that average body size (integrated for the whole community) tends to decrease from reflective to dissipative beaches as community density increases (McLachlan \& Dorvlo 2007b). At the population level, evidence of scaling of population density to body size was previously documented by Defeo \& Cardoso (2004) for the mole crab Emerita brasiliensis. As small body sizes tend to be excluded from coarse sediments, and grain size influences burrowing rate in a variety of sandy beach species (coarse sand usually makes burrowing difficult or impossible; see McLachlan \& Brown 2006), it is expected that body size would follow an inverse pattern compared to density and would thus have an inverse response to beach type.

From the foregoing, it can be concluded that ocean sandy beaches are physically simple and dynamic environments where intertidal benthic macrofauna show fairly clear large-scale patterns of species richness and abundance in response to beach type and latitude. The mechanisms underlying these patterns are mainly related to the physical environment at larger scales, but biological factors may become more important on finer scales under dissipative conditions (Defeo \& McLachlan 2005). The underlying mechanisms are poorly understood, however, and no attempt has yet been made to deconstruct these patterns, i.e. to consider various components of the macrofauna (i.e. benthic fauna retained on a $0.5 \mathrm{~mm}$ sieve) separately. In the present study, we deconstruct the community from a warm temperate microtidal coast in order to better understand richness patterns in relation to variations in the physical beach environment. For this purpose, we compared patterns of richness among taxonomic groups, feeding groups, species with different development modes and semi-terrestrial versus intertidal forms, and we also considered relationships between body size and population density.

\section{MATERIALS AND METHODS}

Database. We collated information from sandy beaches along the warm temperate southwestern Atlantic (WTSA) (Fig. 1) province of South America, which extends from the Valdés Peninsula in Argentina at $41^{\circ} \mathrm{S}$ northwards to Cabo Frio in Brazil at $23^{\circ} \mathrm{S}$ (Sullivan \& Bustamante 1999). A province can be considered as a cohesive unit in ecological terms, and is defined by the presence of common macrofaunal biota (Spalding et al. 2007). We focused on 2 adjacent ecoregions among the 4 that have been defined within this biogeographic province: Southeastern Brazil (SB) and Rio Grande (RG). The SB ecoregion extends $3180 \mathrm{~km}$ 


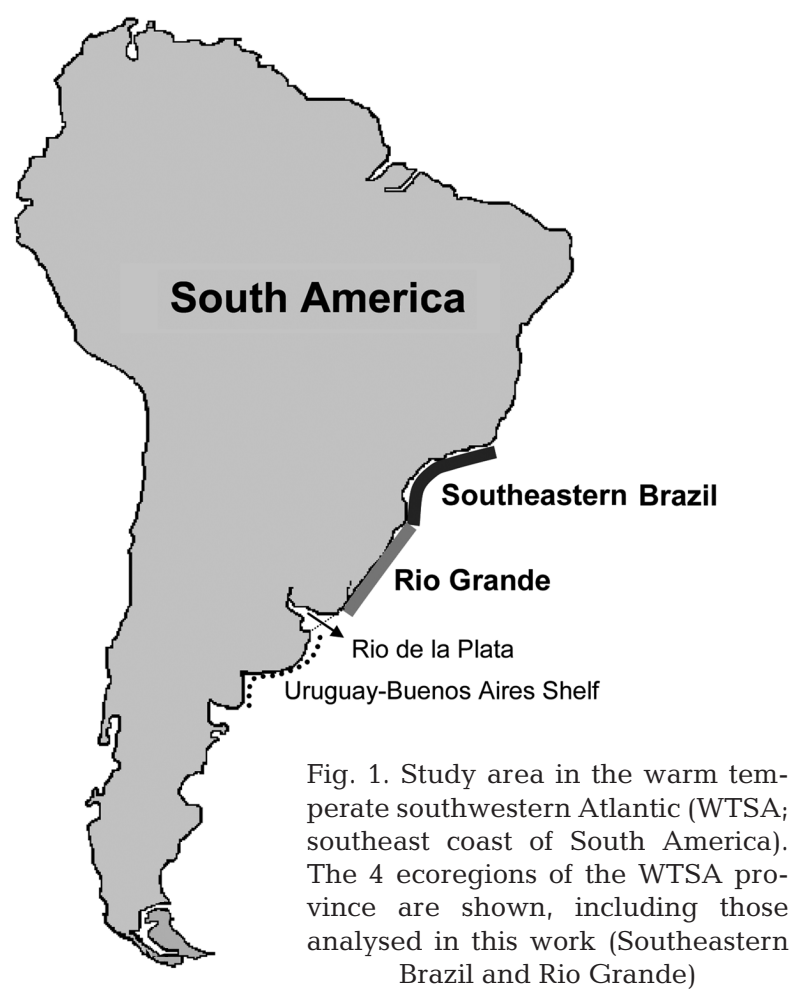

along the Brazilian coast, between northern Cabo Frio at $23^{\circ} \mathrm{S}$ and Cabo de Santa Marta Grande at $28^{\circ} \mathrm{S}$, whereas the RG ecoregion extends $1897 \mathrm{~km}$ from 28 to $35^{\circ} \mathrm{S}$ at Punta del Este in Uruguay. These 2 ecoregions have relatively homogeneous species composition and are fairly distinct from the other 2 ecoregions included within the WTSA (Rio de la Plata and Uruguay-Buenos Aires Shelf; Fig. 1) (Lercari \& Defeo 2006). Indeed, the sandy coast has broadly similar sediment, currents and exposure regimes, uniform tidal range (microtidal, i.e. tidal ranges $<2 \mathrm{~m}$ ), a common bathymetry and a varied coastal geomorphology, which includes a range of beach morphodynamic types (Defeo \& de Álava 2005). Use of beaches within these 2 ecoregions therefore reduces latitudinal effects and eliminates effects of varying tide range on species richness. Nevertheless, we also tested for potential latitudinal trends in our dataset under the null hypothesis that correlation of species richness against latitude was zero, and we found that residuals were not spatially autocorrelated. Thus, we argue that the 2 ecoregions could be considered as a cohesive unit in ecological terms, and we discount potential latitudinal effects in depicting trends.

The literature review involved a search of the primary literature, theses and technical reports of sandy beach surveys performed in the SB and RG ecoregions. Information on the number of species and relevant physical variables was gathered. The community descriptor used was the total number of species recorded per survey (species richness), which was determined as the sum of all species present in each survey. Data on 3 key physical factors were gathered from the respective manuscripts: (1) mean grain size, (2) beach face slope, and (3) the compound index of beach state, known as the dimensionless fall velocity or Dean's parameter $(\Omega)$, which measures how reflective or dissipative a microtidal beach is (Short 1996):

$$
\Omega=\frac{H_{\mathrm{b}}}{W_{\mathrm{s}} \cdot T}
$$

where $H_{\mathrm{b}}$ is breaker height $(\mathrm{m}), W_{\mathrm{s}}$ is sand fall velocity $\left(\mathrm{m} \mathrm{s}^{-1}\right)$ and $T$ is wave period (s). We considered $\Omega$ values $<2$ to characterise reflective beaches and $\Omega$ values $>5$ to define dissipative beaches, with values between 2 and 5 indicating intermediate beach states. Essentially, $\Omega$ is a measure of the ability of the prevalent wave energy to erode sand, and high values characterise dissipative beaches (Defeo \& McLachlan 2005).

Manuscripts were assessed and, when raw data were available, results were verified. We took into account the following cautionary criteria: (1) only those studies that sampled the entire beach width from the lower swash zone up to the drift line or above were considered; in those studies where subtidal samples were taken, these data were not used; (2) when monthly or seasonal surveys were present in the data sources, information was pooled to provide a single estimate for each beach. The final screening reduced our dataset to 63 sandy beach surveys in 2 countries: 50 from Brazil and 13 from Uruguay (Table S1 in the supplement at www.int-res.com/articles/suppl/ m433p029_supp.pdf). When information about a specific physical variable was not present in the paper, an additional bibliographic search for each sandy beach was performed.

Deconstruction approach: defining faunal categories. Species richness was deconstructed using 4 different strategies for species grouping, as well as considering individual species and overall community body size and density, resulting in a total of 6 strategies of analysis:

(1) Taxonomy: 4 categories were recognised: molluscs, polychaetes, crustaceans and insects.

(2) Beach zone occupied: 2 zones were consideredsupralittoral and intertidal-which separate air breathers from water breathers.

(3) Development mode: Following Brown (1983) and Ansell (1983), we broadly classified sandy beach species according to 2 categories of larval development modes: (3.1) species with direct development, restricted dispersal and relatively high potential for isolation, including peracarids (amphipods, isopods), which have internal fertilization, are ovoviviparous and have no pelagic larval stages, and (3.2) species with indirect development and planktonic larvae. The latter cate- 
gory was divided into: (3.2.1) broadcast spawners (e.g. bivalves) with external fertilization, high fecundity, and free-floating planktonic larval stages that can remain in the plankton for variable periods ranging from a few days to months; (3.2.2) species with limited parental care of the eggs and planktonic larvae (e.g. Emerita, whose females carry eggs on pleopods where they are hatched and released as zoea larvae); and (3.2.3) species with lecithotrophic, non-feeding larvae. In both broadcast spawners and those with some parental care, the planktotrophic stages (feeding larvae) develop in the water column, conferring a high dispersal potential leading to stronger gene flow among populations and lower potential for isolation and speciation (Fernández et al. 2009).

(4) Feeding mode: 3 broad categories were recognised, namely filter (suspension) feeders, deposit (sediment) feeders and scavengers/predators.

(5) Species level: We separated the effects of occupied beach zone, development mode and feeding mode at the species level by evaluating the response of 6 species (see Fig. 5) to beach type.

(6) Body size and density: Mean individual body size (as dry mass) was estimated as the ratio between total biomass and total abundance. This analysis was not performed for the whole dataset because not all studies contained estimates of abundance and/or biomass. Moreover, abundance estimates were derived from 2 different units of measurement that are not strictly comparable: density (ind. $\mathrm{m}^{-2}$ ) and abundance, expressed as individuals per strip transect or IST (ind. $\mathrm{m}^{-1}$ ). To convert IST to density estimates, values of beach width $(\mathrm{m})$ for each sampling event are needed. This was impossible to obtain for several reference sources. Thus, only available estimates of density were used to relate body size to density. Variations in mean body size were related to mean grain size, beach face slope and $\Omega$ to test the null hypothesis of absence of differences in individual size across the range of beach morphodynamic types. Density (ind. $\mathrm{m}^{-2}$ ) was also related to beach type.

Statistical analysis. Our general starting hypothesis was that all faunal components, as well as the whole community, would display a trend of increasing richness and abundance from reflective towards dissipative beaches. Relationships between community descriptors and physical variables or $\Omega$ were modelled by linear or nonlinear fitting, which is more appropriate than multiple comparison procedures through discrete categorization (e.g. ANOVAs) of continuous variables to depict large-scale patterns. In all cases, the model that best explained the relationship between biological and physical variables was selected based on $\mathrm{r}^{2}$. In a few cases, data for each beach coming from different years were included as separate entities to perform sta- tistical analyses, following the strategy detailed by Defeo \& Cardoso (2004, see p. 91). Analyses of covariance (ANCOVA) were also used to compare the relationships between species richness and physical descriptors, using beach face slope as the covariate, species richness as the dependent variable, and 5 different strategies for species grouping as the main factors (number of treatments varied in each case). Logarithmic transformations $[\log (\mathrm{x}+1)]$ were made to fulfil the requirements of normality, linearity and homoscedasticity. When significant differences were detected, multiple comparisons were conducted using Scheffe's test $(\alpha=0.05)$.

Generalized linear models (GLM; McCullagh \& Nelder 1989) were used to examine the relationship between total species richness and beach slope, grain size and $\Omega$. Poisson models and a log-link function were used for fitting. Because of potential correlations among covariates, terms were dropped one at a time. Additionally, collinearity was checked using the variance inflation factor (VIF; Montgomery \& Peck 1992). VIF values $>5$ were considered evidence of collinearity, i.e. the information carried by a predictor having such a VIF is contained in a subset of the remaining predictors. In addition, a matrix of Pearson's rank correlation coefficients was computed for all possible pairs of covariates. The Akaike's Information Criterion (AIC) was used to evaluate each model fit and parsimony. Residual plots were evaluated for violations of model assumptions.

\section{RESULTS}

\section{Physical factors}

Sand grain sizes varied between 0.13 and $1.19 \mathrm{~mm}$ and beach face slopes between 0.01 and 0.15 . The full range of morphodynamic states from reflective $(\Omega<2)$ to dissipative $(\Omega>5)$ was present, with the lowest and highest values of $\Omega$ being 0.3 and 8.2, respectively. The steepest beaches had the coarsest sediments and lowest values of $\Omega$, identifying them as reflective beaches, while dissipative beaches showed opposite trends. Relationships between these variables were best explained by exponential models (Fig. 2).

\section{Community patterns}

The 63 beach surveys recorded a total number of 124 species (of which 35 were insects and arachnids) and showed clear patterns of overall macrobenthic community richness against $\Omega$, sand particle size and beach face slope (Fig. 3). Species richness ranged from 4 to 35 

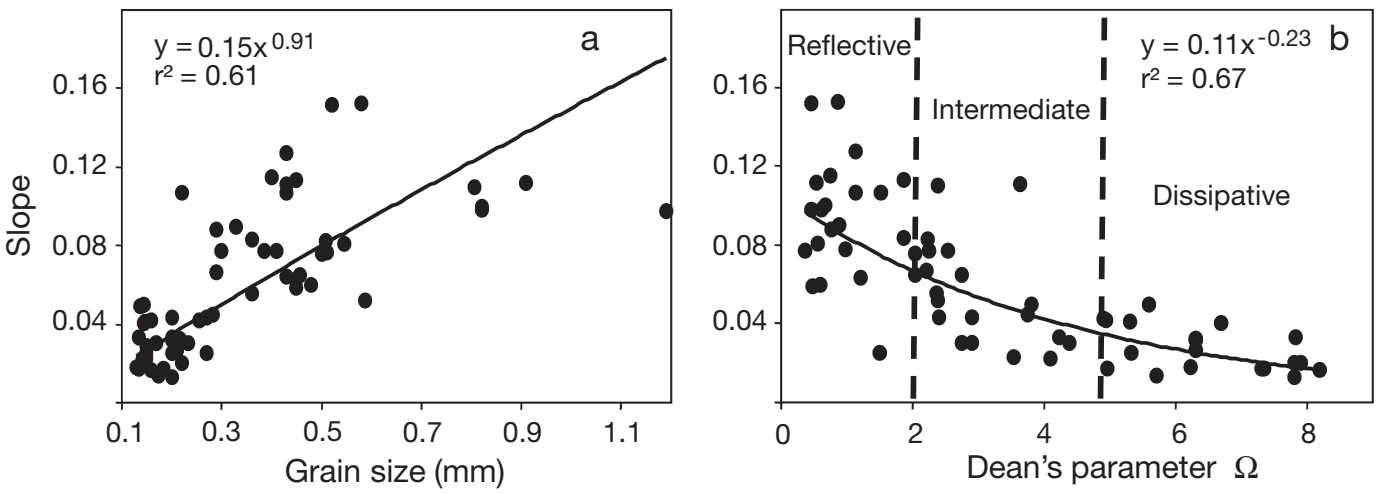

Fig. 2. Best models $(\mathrm{p}<0.001)$ fitted for the relationships between beach face slope and (a) grain size (mm), and (b) Dean's parameter $\Omega$ for beach morphodynamics

marine species (excluding insects and arachnids) per beach and increased exponentially $(\mathrm{p} \ll 0.001)$ with increasing values of $\Omega$, finer grain sizes and flattening beach face slopes, i.e. from reflective to dissipative beach states. Reflective beaches all harboured $<10$ species, whereas dissipative beaches generally harboured $>20$ species. The strongest GLM relationships occurred between species richness and slope and $\Omega$ $\left(\mathrm{r}^{2}=0.65\right.$, AIC $\left.=193.68\right)$, as evidenced by the consistent decrease in the AIC (Table 1). In decreasing order, beach slope and $\Omega$ were the most significant predictors ( $p<0.001$ ) of large-scale variations in species richness, whereas grain size did not have a significant effect when included in the whole model $(p=0.25)$. VIF values ranged from 2.14 to 2.85 (always $<5$ ), and Pearson's rank correlation coefficients for all possible pairs of covariates were always $<0.70$. Both analyses confirmed a lack of any multicollinearity among the covariates that could compromise the interpretability of the GLM results. Thus, beach face slope (a product of the interaction among wave energy, tidal range and particle size) was selected as the most parsimonious variable for doing the deconstructive approach.

\section{Taxonomic deconstruction}

The benthic macrofauna of WTSA sandy beaches included representatives of many phyla, but crustaceans, molluscs and polychaetes predominated, making up $95 \%$ of marine species richness. Deconstruction based on taxonomy indicated that these 3 taxa as well as insects followed the same exponential pattern of increasing richness towards flat slopes and fine sands, with richness tending to level off as beaches became more dissipative; since there were no significant differences in these relationships between polychaetes and molluscs (ANCOVA: p > 0.05), a common regression was fitted for the combined polychaete and mollusc richness (Fig. 4a, Table 2A). The species richness-beach slope relationship significantly differed among taxa (ANCOVA: $F_{2,163}=36.63$, $\mathrm{p} \ll 0.01)$; for a similar beach slope, the number of species was significantly greater for crustaceans than for the polychaete-mollusc group and insects (Scheffe's test: $\mathrm{p}<0.01$ ), indicating that crustaceans had the highest tolerance for coarse sands and reflective beaches.
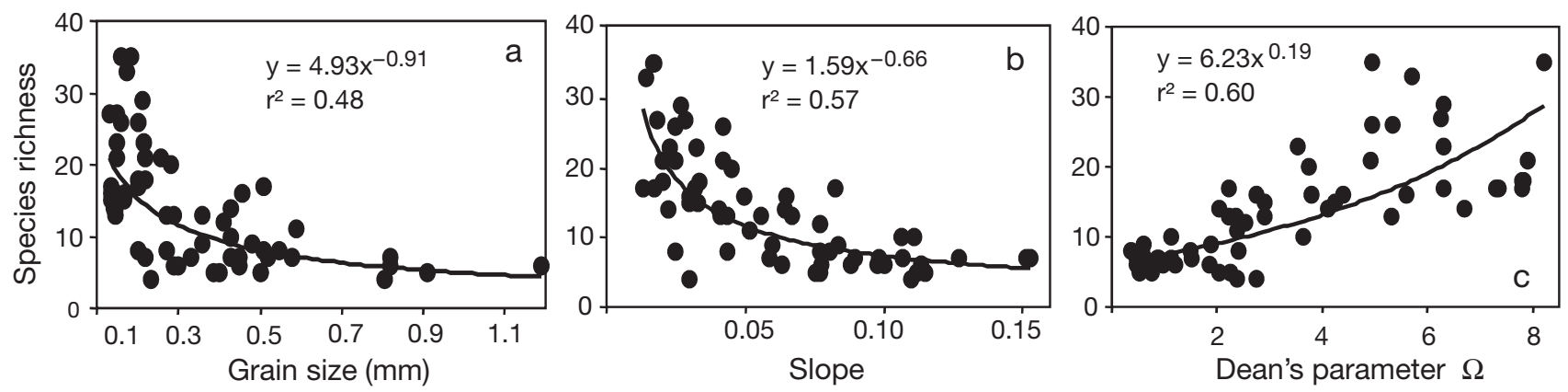

Fig. 3. Best models $(p<0.001)$ for the relationships between total species richness per transect survey against (a) mean grain size, (b) beach face slope, and (c) Dean's parameter $\Omega$ for sandy beaches located in Southeastern Brazil and Rio Grande ecoregions of the warm temperate southwestern Atlantic province 
Table 1. (a) Model building results for the generalized linear model (GLM) for species richness, using beach slope (\%), mean grain size $(\mathrm{mm})$ and Dean's parameter $(\Omega)$ as independent variables, a Poisson distribution function and a log-link function. Akaike Information Criterion (AIC) and likelihood ratio test $\left(\chi^{2}\right)$ are given (in all cases $\mathrm{p}<0.001$ ). Bold italics: best model. (b) Parameter estimates of the best model highlighted in (a). GLM coefficient estimates (mean and SE) are shown together with the Wald statistic (in all cases $\mathrm{p}<0.001$ ). Grain size was not significant in previous models and was removed from the final computations

\begin{tabular}{|c|c|c|c|c|}
\hline $\begin{array}{l}\text { (a) } \\
\text { Variables }\end{array}$ & & $\mathrm{df}$ & AIC & $\chi^{2}$ \\
\hline \multicolumn{2}{|c|}{ Slope $\times$ Dean } & 2 & 193.58 & 177.94 \\
\hline \multicolumn{2}{|c|}{ Grain size $\times$ Slope $\times$ Dean } & 3 & 194.24 & 179.28 \\
\hline \multicolumn{2}{|c|}{ Grain size $\times$ Dean } & 2 & 204.32 & 167.20 \\
\hline \multicolumn{2}{|c|}{ Grain size $\times$ Slope } & 2 & 207.67 & 163.85 \\
\hline \multicolumn{2}{|c|}{ Slope } & 1 & 210.03 & 159.49 \\
\hline \multicolumn{2}{|l|}{ Dean } & 1 & 213.15 & 156.37 \\
\hline \multicolumn{2}{|l|}{ Grain size } & 1 & 249.38 & 120.14 \\
\hline (b) & Estimate & $\mathrm{SE}$ & \multicolumn{2}{|c|}{ Wald statistic } \\
\hline Intercept & 2.68486 & 0.16497 & \multicolumn{2}{|c|}{264.8682} \\
\hline Slope & -7.81636 & 1.71346 & \multicolumn{2}{|c|}{20.8094} \\
\hline Dean & 0.09185 & 0.02149 & \multicolumn{2}{|c|}{18.2771} \\
\hline
\end{tabular}

\section{Deconstruction by development mode}

Following the same pattern depicted by the whole community, a decreasing exponential function between species richness, either with direct development or with a planktonic larval stage, and physical variables was clearly depicted (Fig. 4b). The number of species across beach types did not differ between the 2 development and dispersal modes (ANCOVA: $F_{1,163}=$ $3.37, \mathrm{p}=0.07$ ), indicating that both groups respond in the same way, increasing in species richness from coarse-grained steep (reflective) beaches to finegrained flat (dissipative) beaches (Table 2A).

\section{Deconstruction by feeding guild}

Deconstruction of marine species richness based on feeding guilds (Fig. 4c) revealed significant differences in the species richness-beach slope relationship among groups (ANCOVA: $F_{2,185}=71.31$, p $<0.01$ ). For the same beach slope, deposit feeders were the least diverse feeding group and had the lowest richness on reflective beaches (Scheffe's test: $p<0.01$ ). Scavengers/predators had the highest richness for any

Table 2. (a) Best models ( $\mathrm{p}<0.01$ in all cases) fitted between species richness and beach slope (\%), mean grain size (mm) and Dean's parameter $(\Omega)$. All models are $y=a+b \cdot \ln (x)$, unless denoted by ${ }^{\#} y=a+b x$. (b) Best models fitted between abundance (individuals per strip transect: IST) or density (D) of 6 species and sand particle size (G). ${ }^{*} \mathrm{p}<0.05,{ }^{* *} \mathrm{p}<0.01,{ }^{* * *} \mathrm{p}<0.001$

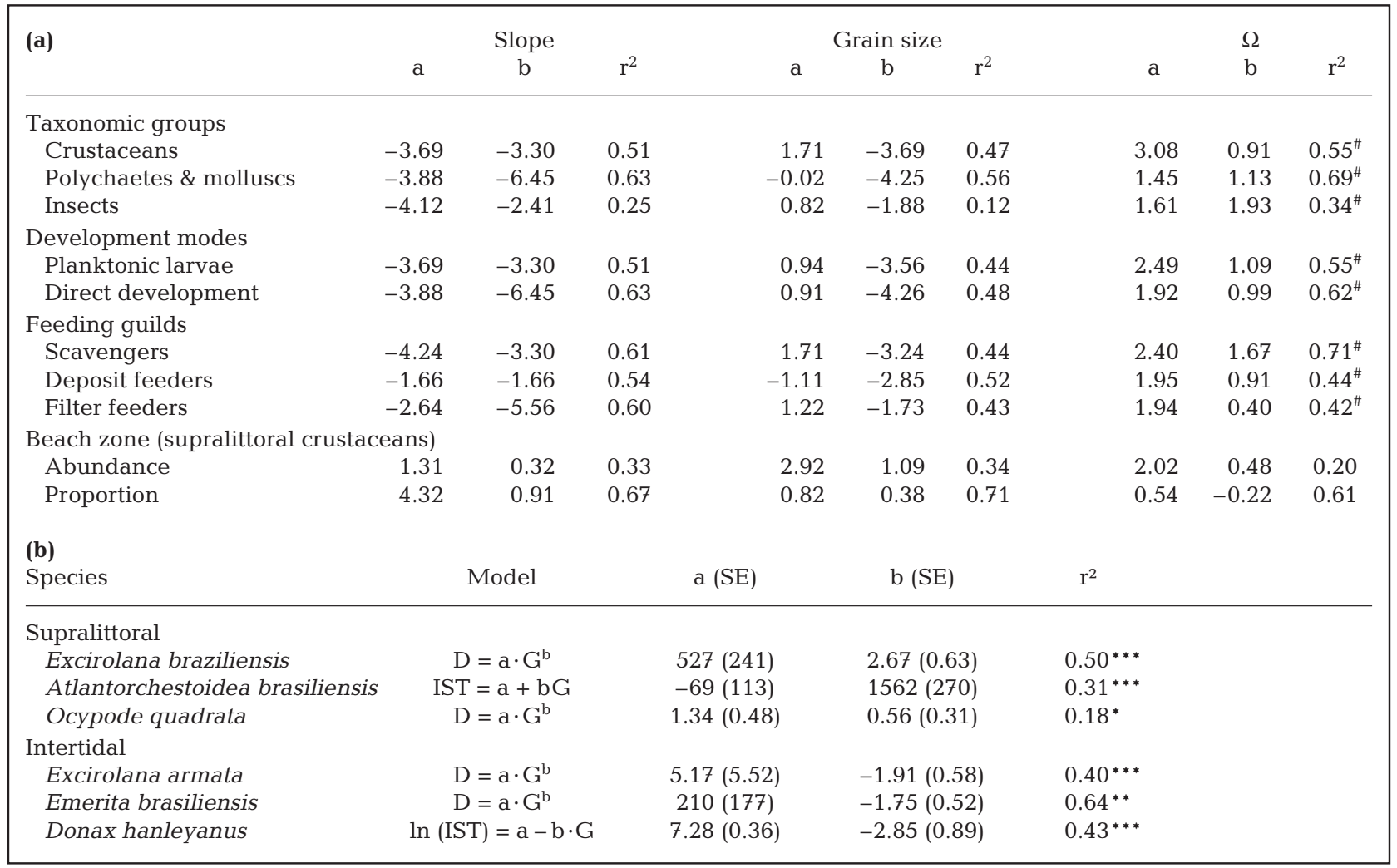




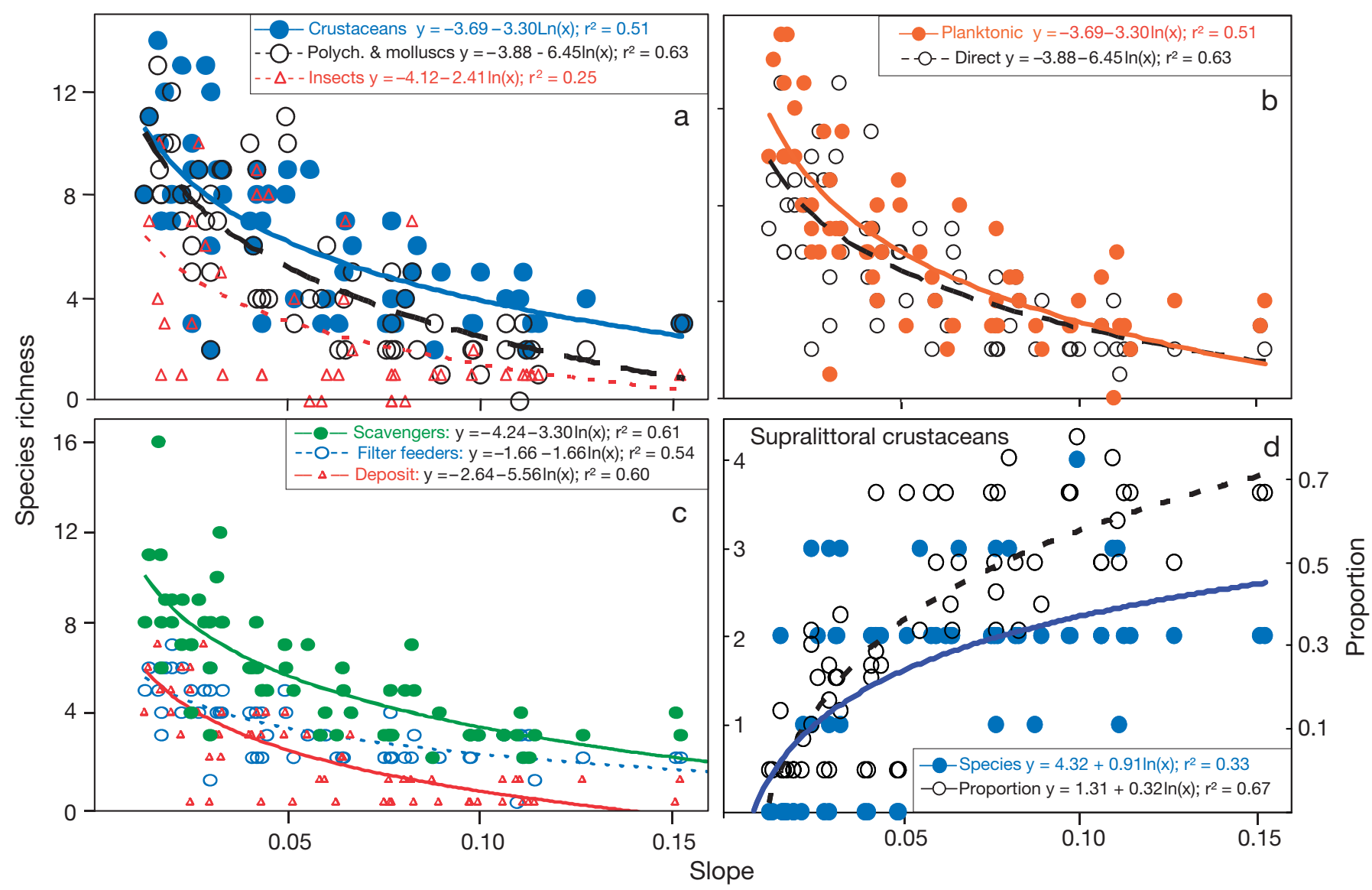

Fig. 4. Deconstruction of marine species richness for sandy beaches located in Southeastern Brazil and Rio Grande ecoregions, showing best models $(p<0.001)$ fitted for species richness against beach face slope: (a) taxonomic groups, (b) development modes, (c) feeding guilds, and (d) proportion and absolute number of supralittoral crustaceans

given slope, indicating their ability to colonise all beach types (Table 2a), with those on reflective beaches being mainly supralittoral crustaceans (Fig. $4 \mathrm{a}, \mathrm{d})$. The regression line of filter feeders had a flatter slope than the other 2 feeding guilds, indicating a more even distribution of species richness of filter feeders across the whole range of morphodynamic types (i.e. some species being on reflective beaches, with species richness slightly increasing towards dissipative beaches; Table 2a).

\section{Deconstruction by zone}

Deconstruction of crustacean species richness based on the beach zone occupied (air breathers vs. water breathers) showed that the proportion of supralittoral species followed the reverse of the trend found for all other macrofaunal components, increasing significantly towards reflective beaches (i.e. beaches with low $\Omega$, coarser grains and steep slopes; Fig. $4 \mathrm{~d}$,
Table 2A). Supralittoral species made up almost $80 \%$ of the total crustacean species on reflective beaches, but this proportion decreased to $<10 \%$ on dissipative beaches (Fig. 4d). At beach slopes $<0.05$ (Fig. 4d) and grain sizes $\leq 0.20 \mathrm{~mm}$, the proportion of supralittoral crustaceans was close to 0 , whereas they represented up to $75 \%$ of the total number of crustacean species at slopes $>0.10$ and grain sizes $>0.60 \mathrm{~mm}$. The absolute number of supralittoral crustacean species also increased with beach slope and tended to stabilize at 3 species in beaches with the steepest slopes (Fig. 4d) and coarsest sands, i.e. reflective conditions (Table 2a).

\section{Species level comparisons}

The foregoing results suggest contrasting responses of sandy beach crustacean species to morphodynamics according to their location across-shore rather than taxonomy, development mode or feeding guild: supralittoral forms showed higher richness on reflec- 
tive beaches, which is the reverse of the pattern followed by truly intertidal species (Table 2b). Responses of individual species to beach type in terms of abundance or density confirm this (Fig. 5). Supralittoral species: the ubiquitous peracarids Excirolana braziliensis (Fig. 5a) and Atlantorchestoidea brasiliensis (Fig. 5b) and the ghost crab Ocypode quadrata (Fig. 5c), which is a top predator in the sandy beach system, all increased in abundance from dissipative to reflective beaches. In contrast, the abundance of 3 intertidal species, the peracarid Excirolana armata (Fig. 5d), the mole crab Emerita brasiliensis (Fig. 5e) and the wedge
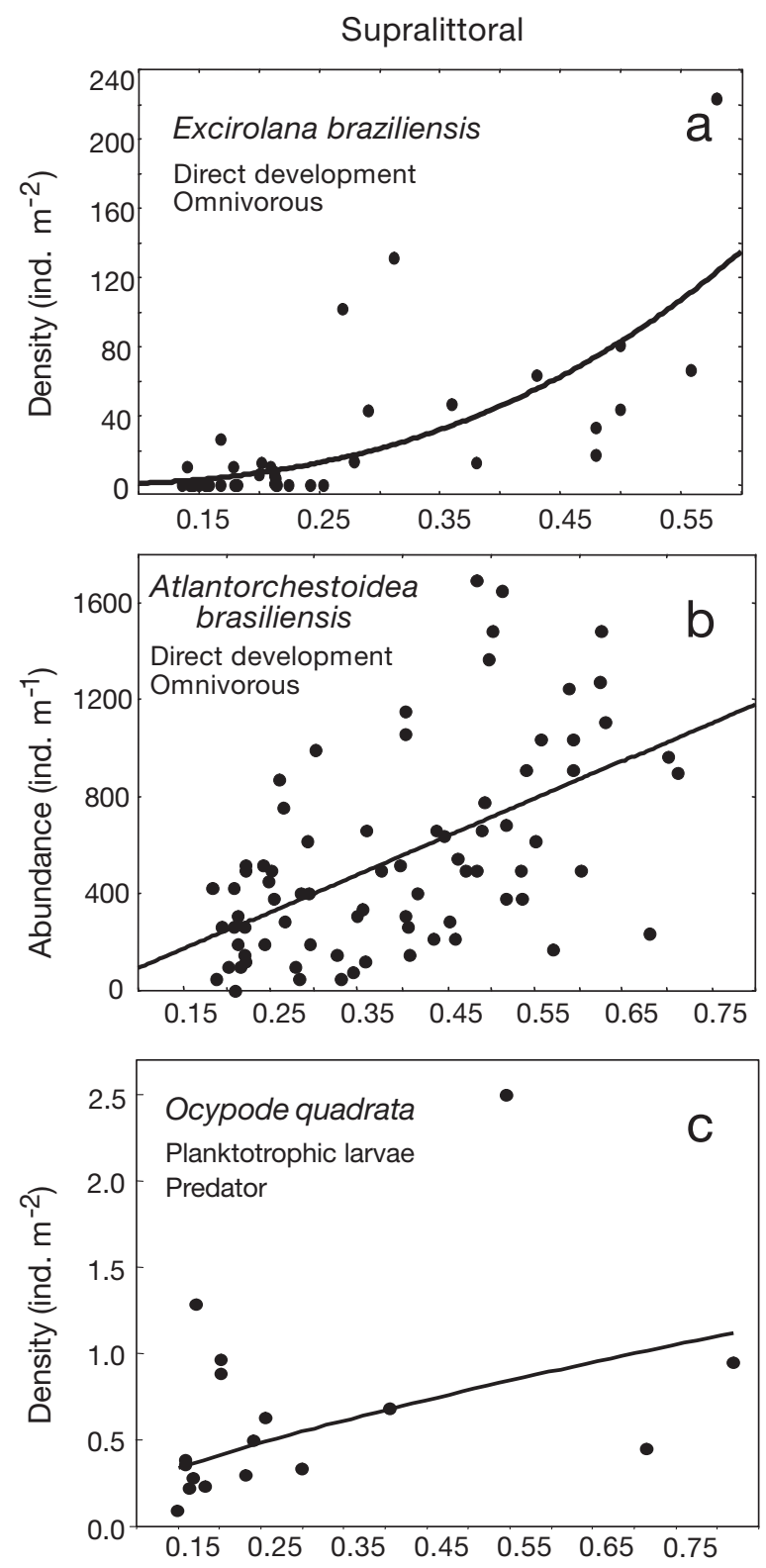

clam Donax hanleyanus (Fig. 5f), increased from reflective to dissipative beaches. Thus, supralittoral and intertidal species showed opposite responses to beach type regardless of their taxonomic group or mode of development and feeding (Table $2 b$ ).

\section{Density, body size and beach types}

Density (D) ranged from 30 to $>1000$ ind. $\mathrm{m}^{-2}$, increasing with finer grain size, flatter slopes and thus from reflective to dissipative beaches. Among physical
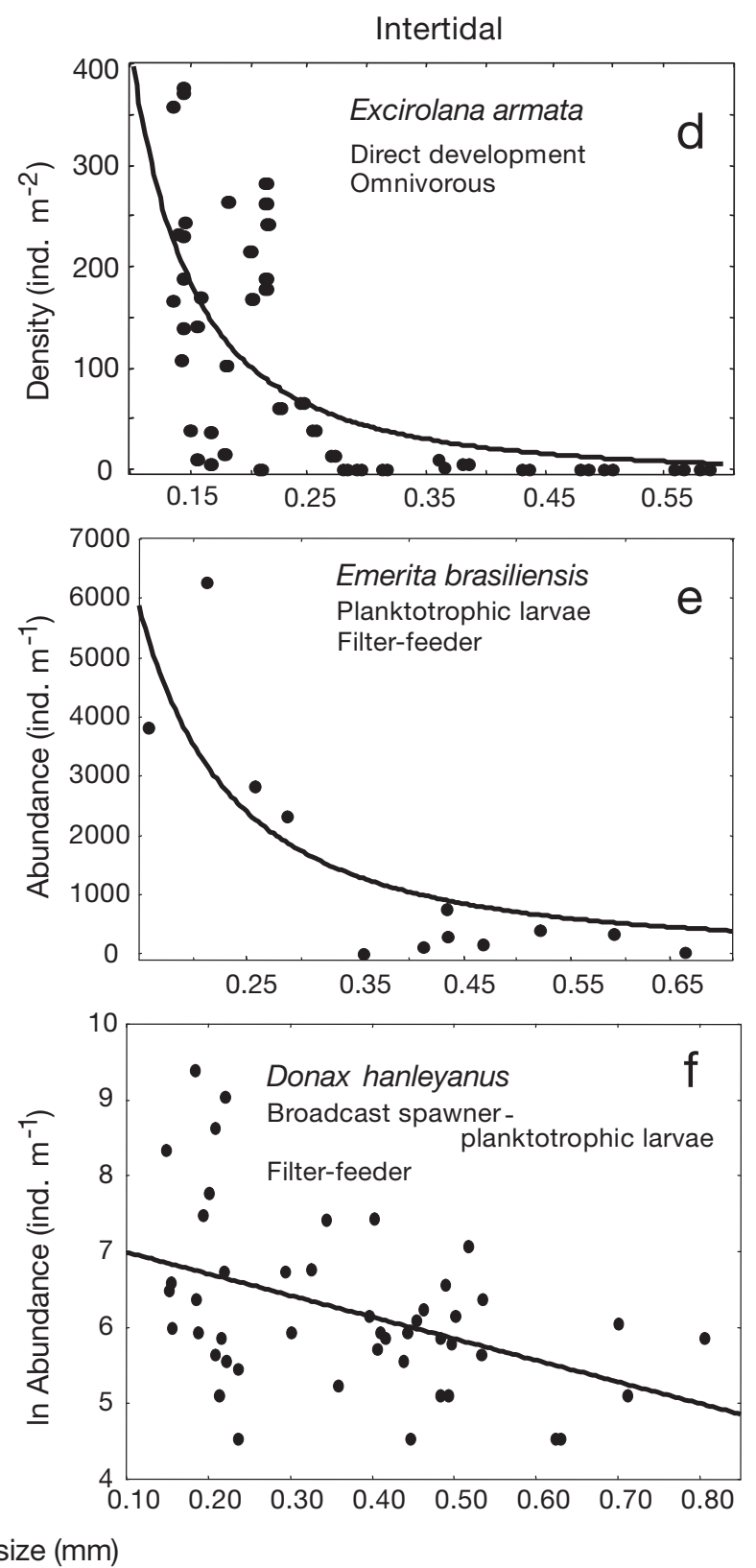

Grain size (mm)

Fig. 5. Best models $(p<0.001)$ fitted between abundance or density of 6 species and particle size. (a-c) Supralittoral and $(d-f)$ intertidal species with different development and feeding strategies (indicated in each panel) 
variables, beach face slope showed the strongest relationship with density, i.e. density decreased exponentially with steeper slopes (Fig. 6a). Mean individual body size $\left(\mathrm{M}_{\mathrm{d}}\right.$, individual dry mass) ranged between 0.4 and $119 \mathrm{mg}$, and followed the inverse pattern as that of density, increasing exponentially from dissipative to reflective beaches, i.e. with steeper slopes
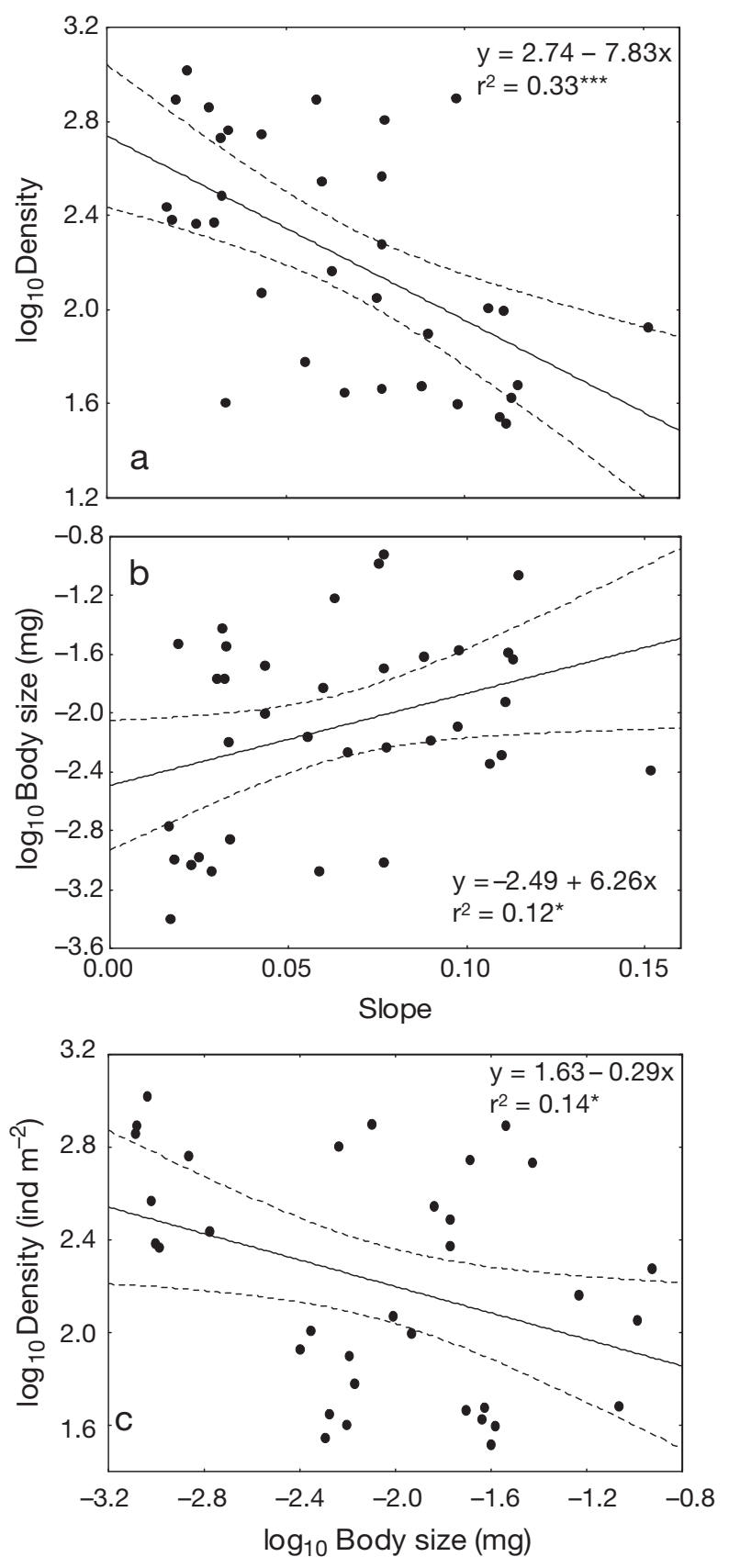

Fig. 6. Best linearised (log values) regression models fitted between beach face slope and (a) body size, or (b) density, or (c) between density and body size. (----): $95 \%$ CIs for the fitted regressions. ${ }^{*} \mathrm{p}<0.05,{ }^{* * *} \mathrm{p}<0.001$
(Fig. 6b). Body size and density therefore showed inverse responses to beach type. Combining the above patterns, an inverse relationship $\left(\mathrm{r}^{2}=0.14\right.$; $\left.\mathrm{p}<0.05\right)$ between log population density and log body size was found, according to the model (Fig. 6c): $\log (\mathrm{D})=1.63-$ $0.29 \log \left(M_{d}\right)$. Thus, dissipative beaches harbour communities with the highest densities and species with the smallest mean individual body sizes. These largescale patterns in abundance and body weight indicate a scaling of population density to body size in sandy beach communities.

\section{DISCUSSION}

The strong relationships among slope, particle size and $\Omega$ indicate that all 3 parameters can be used as measures of beach type. Although $\Omega$ is considered to be the least precise because of the difficulty of obtaining accurate long-term average data on wave height and period, GLM analysis showed that beach slope and $\Omega$ were the best explanatory variables of overall community species richness (Table 1). The aggregated nature of both variables $(\Omega$ integrates variability in wave climate and particle size, and beach slope results from the interaction among wave energy, tidal range and particle size) may indicate that overall beach state, and not any single variable, influences macrobenthic species richness on sandy beaches. Thus, richness in macrobenthic communities on WTSA sandy beaches increased as beaches became more dissipative. However, although overall community species richness showed an exponential increase towards dissipative beaches, subsequent analyses with various deconstructed groups suggested that, in some specific cases, group responses differed from the aggregate response.

Deconstruction by taxon shows that molluscs and polychaetes followed the overall community trend of decreasing numbers of species towards reflective beaches. Crustaceans showed a more complex response as they tend to separate into 2 groups: intertidal and supralittoral forms. Crustaceans have the highest number of intertidal species that are able to colonise beaches of coarse sand and steep slopes because they are most mobile, have better burrowing abilities, can best cope with dynamic swash, and their exoskeletons provide some protection from the abrasive effects of coarse sand. Further, supralittoral crustaceans were most abundant in reflective beaches, accounting for a small pool of species that are successful at this extreme beach state. However, supralittoral insects showed a response opposite to that of supralittoral crustaceans. Since insect distribution extends landwards rather than seawards unlike the other marine groups, this trend may be part of a larger pic- 
ture which we are missing by not sampling the dunes. Wider sampling and further deconstruction on insects is required to clarify this and to separate endemic beach forms from migrants and flying from flightless forms.

Deconstruction by development mode showed an even split between species with planktonic larvae and those with direct development. Both groups increased in species numbers towards dissipative beach states, and subsequent analysis showed this trend to be closely correlated with feeding guilds. Filter feeders had planktonic larvae, whereas scavengers/predators had direct development, with few exceptions (Fig. S1 in the supplement at www.int-res.com/articles/suppl/ m433p029_supp.pdf). The close relationship among feeding guilds and development modes could be explained by the inherent characteristics of life history traits. Indeed, scavengers/predators are highly mobile, less dependent on larval dispersal and may thus have direct development, whereas filter feeders are more sedentary and thus need planktonic larvae for dispersal. The patterns found may also be related to the availability and constancy of food supply, which would be more erratic and unpredictable for scavengers/ predators.

Species richness patterns for feeding groups matched the general trends. Deposit feeders were sparse in general and absent towards reflective beaches, as dynamic, well drained conditions and high permeability in reflective beaches are not conducive to accumulation of organic material in the sediment (McLachlan \& Brown 2006). The deposit feeding mode only became prevalent in finer sands with higher organic content, as found on dissipative beaches. Scavengers/predators were successful on all beach types and their diversity highlights the role of beaches as interfaces that receive and process materials of marine origin. The flat slope of the regression line of species richness versus beach slope for filter feeders suggests that they can colonise beaches of the reflective type but there is little addition of species towards dissipative beaches; rather, a few species can become extremely abundant, as usually occurs on dissipative beaches (Defeo \& McLachlan 2005). Filter feeders require inundation to feed and therefore only occur in the lower half of the intertidal zone, whereas scavengers occur throughout the intertidal and dominate the supralittoral. Thus, there are more spatial niches for scavengers than for filter feeders, the latter occupying only a third of the vertical area available to the former.

Among the marine forms, only the crustaceans include both intertidal and supralittoral species. Deconstruction between supralittoral and intertidal forms, i.e. based on shore zones occupied, showed that supralittoral crustaceans were more diverse on reflec- tive beaches (Fig. 4d). A group of 3 supralittoral species was able to occur even under the most reflective conditions, which was also noted by Defeo \& Gómez (2005), Lastra et al. (2009) and Fanini et al. (2009). Further support for a different response in supralittoral forms comes from Incera et al. (2006), who found that supralittoral species were less affected by beach face slope, i.e. morphodynamic type, than intertidal species. This reverse trend in supralittoral marine forms is not related to development mode since it is displayed both in forms with direct development and in those with planktonic larvae. Indeed, consideration of individual species showed that zone was more important than either development or feeding modes in determining species richness responses to beach type. Trends in individual species abundance or density across beach types were clear in all cases, except possibly in the brachyuran ghost crab Ocypode quadrata. However, Turra et al. (2005) and da Rosa \& Borzone (2008) also found Ocypode on beaches with coarse sands. Ghost crabs may migrate back toward the dunes and burrow there for shelter during storms (Hobbs et al. 2008).

Trends in body size and density support the findings of an earlier global analysis by McLachlan \& Dorvlo (2007b), namely that densities increase by some orders of magnitude from reflective to dissipative beaches as mirrored by a decrease in mean individual body size. They suggested that the less abrasive and less turbulent conditions on dissipative beaches enable the establishment of less robust species, which cannot tolerate the turbulent swash and coarse sand under reflective conditions. Similarly, Incera et al. (2006) noted that steeper (more reflective) beaches harboured a significantly higher percentage of active burrowers, especially at lower shore levels, whereas non-active burrowers were more prevalent on flat (more dissipative) beaches. Increasing densities also provide more scope for biological interactions that structure the community under dissipative conditions.

Several models have been proposed to explain macroscale patterns in species richness on sandy beaches. Because of the physically controlled nature of beaches and the relative simplicity of the beach environment (it can be defined in terms of sand particle size, tidal regime and wave climate), these models have focused on explanations revolving around physical rather than biological control. The Swash Exclusion Hypothesis (McLachlan et al. 1993) postulated that the harsher swash climate on reflective beaches excluded species since the swash climate on the beach face is closely related to beach type (McArdle \& McLachlan 1991, 1992). The term 'harsh' is used here to denote an environment that is dominated by extreme abiotic factors (sensu Begon et al. 2006, p. 611). In sandy beaches, the extreme is the interaction between coarse sand and 
turbulent swash, which has been widely documented through experimental and field work (reviewed by Defeo \& McLachlan 2005) to make burrowing almost impossible, resulting in a decrease in growth, condition, survival and reproduction rates (i.e. fitness). Thus, these factors contribute to making reflective beach environments physically harsh for intertidal macrofauna (Brazeiro 2001, Papageorgiou et al. 2006). The Habitat Harshness Hypothesis postulated that in harsh reflective beaches, organisms must divert more energy towards maintenance, resulting in less energy available for reproduction, with consequent higher mortality (Defeo et al. 2001, Defeo \& Martínez 2003). A third hypothesis, the Habitat Safety Hypothesis, separated intertidal and supralittoral forms, taking into account both swash and sand effects and differences in life histories. This hypothesis suggested that supralittoral species have higher growth, survival and reproduction rates on microtidal reflective beaches (Defeo \& Gómez 2005). The presence of a berm that is not inundated makes reflective beaches the most stable beach type with low backshore mobility (Short 1996), favouring the development of supralittoral species (that are not affected by the interaction between coarse sand and turbulent swash) in a more stable and safer environment because their risk of immersion is substantially lower here than on dissipative beaches. The latter 2 hypotheses are more applicable at the population than at the community level, for which the first was formulated.

The results of our deconstructive meta-analysis support the theoretical framework of these hypotheses, providing more detailed insights into causative factors and raising new questions for further investigation. The conceptual diagram depicted in Fig. 7 shows the general applicability of the Autecological Hypothesis (which states that in physically controlled environments, communities are structured by the independent responses of individual species to the abiotic environment) across the range of beach types in the absence of latitudinal and tidal effects, but with decreasing habitat harshness towards dissipative conditions where biological factors may become more important in structuring sandy beach communities. For all categories, groups and guilds in the intertidal, the Swash Exclusion and Habitat Harshness Hypotheses, which predict species exclusion by harsh swash and coarse sand, are supported. The increase in species richness and abundance shown by supralittoral crustaceans towards reflective beaches in our meta-analysis supports the Habitat Safety Hypothesis. However, predictions were not supported for insects, on which more work is required. Relationships among feeding, reproduction, abundance and beach type at the species level also need further study.

In summary, the deconstruction approach provided insights into species richness and abundance patterns according to life cycle characteristics and was useful in quantifying the relative importance of physical environment changes on macrofaunal components. Changes and gradients in the physical environment explain much of the meta-scale variation in community structure in sandy beaches. This has been evidenced by increases in species richness and density and decreases in body size from harsh reflective to dissipative beaches. All sub-components of the intertidal com-
Fig. 7. Conceptual model of species richness response to beach type. Intertidal species richness increases from reflective to dissipative beaches. The direction of arrows for groups denotes increasing patterns in species richness in response to beach type, as determined in the deconstructive meta-analysis presented in this paper. The theoretical framework for sandy beach ecology is shown, including the general Autecological Hypothesis and more specific hypotheses defined for sandy beach intertidal and supralittoral macrofauna: the Swash Exclusion Hypothesis, the Habitat Harshness Hypothesis and the Hypothesis of Habitat Safety (see 'Discussion' for full explanation of these hypotheses)

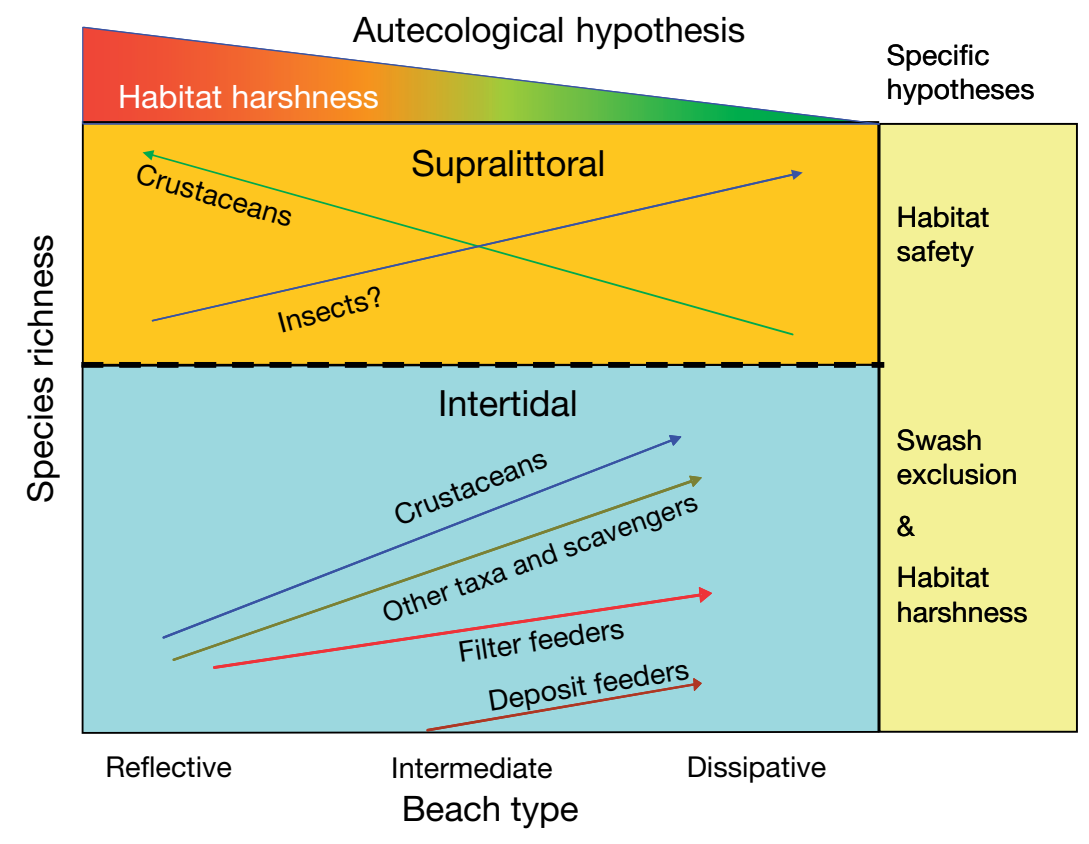


munity (taxa, feeding groups and guilds) show the same response, varying only in where they appear along the gradient of habitat harshness, and by how quickly they respond to decreasing harshness by increasing species richness. However, the single exception (a reverse response in the case of supralittoral crustaceans, i.e. increasing species richness and abundance with increasing harshness) confirms the influence of a different suite of controlling factors (e.g. beach stability) for air breathers above the drift line. Finally, feeding and larval dispersal are closely coupled to the nature, productivity and circulation of inshore waters, and the links between feeding and development modes may be an indication of this.

Acknowledgements. We thank M. Seaman, N. L. Gutiérrez, J. Gómez, L. Ortega, C. Peterson and 4 anonymous referees for useful comments. O.D. acknowledges support from The Pew Charitable Trusts, CONICYT (Project Nos. 1018 and 4034), PDT (Project S/C/OP/07/49) and DINARA (UTF/URU/025/ URU).

\section{LITERATURE CITED}

Ansell AD (1983) Biology of the genus Donax. In: McLachlan A, Erasmus T (eds) Sandy beaches as ecosystems. Junk, The Hague, p 607-636

Begon M, Townsend CR, Harper JL (2006) Ecology: from individuals to ecosystems. Blackwell, Oxford

Blamires D, de Oliveira G, Barreto B de S, Diniz-Filho JAF (2008) Habitat use and deconstruction of richness patterns in Cerrado birds. Acta Oecol 33:97-104

Bonada N, Murria C, Zamora-Munoz C, El Alawi M and others (2009) Using community and population approaches to understand how contemporary and historical factors have shaped species distribution in river systems. Glob Ecol Biogeogr 18:202-213

> Brazeiro A (2001) The relationship between species richness and morphodynamics in sandy beaches: which are the underlying factors? Mar Ecol Prog Ser 224:35-44

Brown AC (1983) The ecophysiology of sandy beach fauna: a partial review. In: McLachlan A, Erasmus T (eds) Sandy beaches as ecosystems. Junk, The Hague, p 575-605

> Celentano E, Gutiérrez N, Defeo O (2010) Effects of morphodynamic and estuarine gradients on the demography and distribution of a sandy beach mole crab: implications for source-sink habitat dynamics. Mar Ecol Prog Ser 398: 193-205

Currie DJ, Mittelbach GG, Cornell HV, Field R and others (2004) Predictions and tests of climate-based hypotheses of broad-scale variation in taxonomic richness. Ecol Lett 7:1121-1134

da Rosa L, Borzone CA (2008) Spatial distribution of Ocypode quadrata (Crustacea: Ocypodidae) along estuarine environments in the Paranaguá Bay Complex, Southern Brazil. Rev Bras Zool 25:383-388

de Álava A, Defeo O (1991) Distributional pattern and population dynamics of Excirolana armata (Isopoda: Cirolanidae) in an Uruguayan sandy beach. Estuar Coast Shelf Sci 33:433-444

> Defeo O, Cardoso R (2004) Latitudinal patterns in abundance and life-history traits of the mole crab Emerita brasiliensis on South American sandy beaches. Divers Distrib 10: 89-98
Defeo O, de Álava A (2005) South America, coastal ecology: sandy beaches ecosystems in South America. In: Schwartz ML (ed) Encyclopedia of coastal science. Springer, Dordrecht, p 888-892

Defeo O, Gómez J (2005) Morphodynamics and habitat safety in sandy beaches: life history adaptations in a supralittoral amphipod. Mar Ecol Prog Ser 293:143-153

Defeo O, Martínez G (2003) The habitat harshness hypothesis revisited: life history of the isopod Excirolana braziliensis in sandy beaches with contrasting morphodynamics. J Mar Biol Assoc UK 83:331-340

Defeo O, McLachlan A (2005) Patterns, processes and regulatory mechanisms in sandy beach macrofauna. Mar Ecol Prog Ser 295:1-20

Defeo O, Jaramillo E, Lyonnet A (1992) Community structure and intertidal zonation of the macroinfauna in the Atlantic coast of Uruguay. J Coast Res 8:830-839

$>$ Defeo O, Brazeiro A, de Alava A, Riestra G (1997) Is sandy beach macroinfauna only physically controlled? Role of substrate and competition in isopods. Estuar Coast Shelf Sci 45:453-462

> Defeo O, Gómez J, Lercari D (2001) Testing the swash exclusion hypothesis in sandy beach populations: the mole crab Emerita brasiliensis in Uruguay. Mar Ecol Prog Ser 212:159-170

Fanini L, Defeo O, Do Santos C, Scapini F (2009) Testing the Habitat Safety Hypothesis with behavioural field experiments: amphipod orientation on sandy beaches with contrasting morphodynamics. Mar Ecol Prog Ser 392: 133-141

Fernández M, Astorga A, Navarrete SA, Valdovinos C, Marquet PA (2009) Deconstructing latitudinal species richness patterns in the ocean: does larval development hold the clue? Ecol Lett 12:601-611

Field R, Hawkins BA, Cornell HV, Currie DJ and others (2009) Spatial species-richness gradients across scales: a metaanalysis. J Biogeogr 36:132-147

Hobbs CH III, Landry CB, Perry JE III (2008) Assessing anthropogenic and natural impacts on ghost crabs (Ocypode quadrata) at Cape Hatteras National Seashore, North Carolina. J Coast Res 24:1450-1458

Incera M, Lastra M, López J (2006) Effect of swash climate and food availability on sandy beach macrofauna along the NW coast of the Iberian Peninsula. Mar Ecol Prog Ser 314:25-33

> Jaramillo E, McLachlan A, Dugan J (1995) Total sample area and estimates of species richness in exposed sandy beaches. Mar Ecol Prog Ser 119:311-314

Lastra M, Schlacher T, Olabarria C (2009) Niche segregation in sandy beach animals: an analysis with surface-active peracarid crustaceans on the Atlantic coast of Spain. Mar Biol 157:613-625

Lercari D, Defeo O (2006) Large-scale diversity and abundance trends in sandy beach macrofauna along full gradients of salinity and morphodynamics. Estuar Coast Shelf Sci 68:27-35

> Lozoya JP, Defeo O (2006) Effects of a freshwater canal discharge on an ovoviviparous isopod in an exposed sandy beach. Mar Freshw Res 57:421-428

Marquet PA, Fernandez M, Navarrete SA, Valdovinos C (2004) Diversity emerging: toward a deconstruction of biodiversity patterns. In: Lomolino M, Heaney LR (eds) Frontiers of biogeography: new directions in the geography of nature. Sinauer Associates, Sunderland, MA, p 191-209

McArdle S, McLachlan A (1991) Dynamics of the swash zone and effluent line on sandy beaches. Mar Ecol Prog Ser 76: 91-99 
McArdle S, McLachlan A (1992) Sandy beach ecology: swash features relevant to the macrofauna. J Coast Res 8: 398-407

McCullagh P, Nelder JA (1989) Generalized linear models. Chapman \& Hall, London

McLachlan A (1990) Dissipative beaches and macrofauna communities on exposed intertidal sands. J Coast Res 6: $57-71$

McLachlan A, Brown AC (2006) The ecology of sandy shores. Elsevier, Burlington, MA

McLachlan A, Dorvlo A (2005) Global patterns in sandy beach macrobenthic communities. J Coast Res 21:674-687

McLachlan A, Dorvlo A (2007a) Species-area relationships for sandy beach macrobenthos in the context of intertidal width. Oceanologia 49:91-98

McLachlan A, Dorvlo A (2007b) Global patterns in sandy beach macrofauna communities: biological factors. J Coast Res 23:1081-1087

McLachlan A, Woodridge T, Dye AH (1981) The ecology of sandy beaches in southern Africa. S Afr J Zool 16:219-231

McLachlan A, Jaramillo E, Donn TE, Wessels F (1993) Sand beach macrofauna communities: a geographical comparison. J Coast Res 15:27-38

Montgomery DC, Peck EA (1992) Introduction to linear regression analysis, 2nd edn. John Wiley \& Sons, New York, NY

Papageorgiou N, Arvanitidis C, Eleftheriou A (2006) Multi-

Editorial responsibility: Charles Peterson,

Morehead City, North Carolina, USA causal environmental severity: a flexible framework for microtidal sandy beaches and the role of polychaetes as an indicator taxon. Estuar Coast Shelf Sci 70:643-653

Sanders HL (1968) Marine benthic diversity: a comparative study. Am Nat 102:243-282

Short AD (1996) The role of wave height, period, slope, tide range and embaymentisation in beach classification: a review. Rev Chil Hist Nat 69:589-604

Soares AG (2003) Sandy beach morphodynamics and macrobenthic communities in temperate, subtropical and tropical regions - a macroecological approach. PhD thesis, University of Port Elizabeth

Spalding MD, Fox HE, Allen GR, Davidson N and others (2007) Marine ecoregions of the world: a bioregionalization of coastal and shelf areas. Bioscience 57:573-583

Sullivan SK, Bustamante G (1999) Setting geographic priorities for marine conservation in Latin America and the Caribbean. The Nature Conservancy, Arlington, VA

Terribile LC, Diniz-Filho JAF, Rodriquez MA, Rangel TFLVB (2009) Richness patterns, species distributions and the principle of extreme deconstruction. Glob Ecol Biogeogr 18:123-136

Turra AO, Gonçalves MAO, Denadai MR (2005) Spatial distribution of the ghost crab Ocypode quadrata in low-energy tide-dominated sandy beaches. J Nat Hist 39:2163-2177

Wiens JJ, Donoghue MJ (2004) Historical biogeography, ecology and species richness. Trends Ecol Evol 19:639-644

Submitted: February 9, 2011; Accepted: May 10, 2011

Proofs received from author(s): June 29, 2011 